\title{
Direct glucose production from lignocellulose using Clostridium thermocellum cultures supplemented with a thermostable $\beta$-glucosidase
}

Panida Prawitwong ${ }^{1}$, Rattiya Waeonukul ${ }^{2}$, Chakrit Tachaapaikoon², Patthra Pason ${ }^{2}$, Khanok Ratanakhanokchai ${ }^{3}$, Lan Deng ${ }^{1}$, Junjarus Sermsathanaswadi ${ }^{3}$, Krisna Septiningrum ${ }^{1,4}$, Yutaka Mori ${ }^{1}$ and Akihiko Kosugi ${ }^{1,4^{*}}$

\begin{abstract}
Background: Cellulases continue to be one of the major costs associated with the lignocellulose hydrolysis process. Clostridium thermocellum is an anaerobic, thermophilic, cellulolytic bacterium that produces cellulosomes capable of efficiently degrading plant cell walls. The end-product cellobiose, however, inhibits degradation. To maximize the cellulolytic ability of $C$. thermocellum, it is important to eliminate this end-product inhibition.

Results: This work describes a system for biological saccharification that leads to glucose production following hydrolysis of lignocellulosic biomass. C. thermocellum cultures supplemented with thermostable beta-glucosidases make up this system. This approach does not require any supplementation with cellulases and hemicellulases. When C. thermocellum strain S14 was cultured with a Thermoanaerobacter brockii beta-glucosidase (CgIT with activity $30 \mathrm{U} / \mathrm{g}$ cellulose) in medium containing $100 \mathrm{~g} / \mathrm{L}$ cellulose (617 mM initial glucose equivalents), we observed not only high degradation of cellulose, but also accumulation of $426 \mathrm{mM}$ glucose in the culture broth. In contrast, cultures without CgIT, or with less thermostable beta-glucosidases, did not efficiently hydrolyze cellulose and accumulated high levels of glucose. Glucose production required a cellulose load of over $10 \mathrm{~g} / \mathrm{L}$. When alkalipretreated rice straw containing $100 \mathrm{~g} / \mathrm{L}$ glucan was used as the lignocellulosic biomass, approximately $72 \%$ of the glucan was saccharified, and glucose accumulated to $446 \mathrm{mM}$ in the culture broth. The hydrolysate slurry containing glucose was directly fermented to $694 \mathrm{mM}$ ethanol by addition of Saccharomyces cerevisiae, giving an $85 \%$ theoretical yield without any inhibition.
\end{abstract}

Conclusions: Our process is the first instance of biological saccharification with exclusive production and accumulation of glucose from lignocellulosic biomass. The key to its success was the use of $C$. thermocellum supplemented with a thermostable beta-glucosidase and cultured under a high cellulose load. We named this approach biological simultaneous enzyme production and saccharification (BSES). BSES may resolve a significant barrier to economical production by providing a platform for production of fermentable sugars with reduced enzyme amounts.

Keywords: Clostridium thermocellum, $\beta$-glucosidases, Glucose production, Biological saccharification, Cellulosomes

\footnotetext{
* Correspondence: akosugi@affrc.go.jp

${ }^{1}$ Biological Resources and Post-harvest Division, Japan International Research

Center for Agricultural Sciences (JIRCAS), 1-1 Ohwashi, Tsukuba, Ibaraki

305-8686, Japan

${ }^{4}$ University of Tsukuba Graduate School of Life and Environmental

Sciences, 1-1-1 Ten-noudai, Tsukuba, Ibaraki 305-8572, Japan

Full list of author information is available at the end of the article
} 


\section{Background}

Many microorganisms capable of producing cellulose and hemicellulose-degrading enzymes have been reported and characterized [1]. Clostridium thermocellum, an anaerobic, thermophilic, spore-forming bacterium, is the most potent cellulose-degrading bacterium known to produce cellulosomes [2]. The cellulosomes of C. thermocellum contain a surprisingly large variety of enzymes and show attractive enzymatic properties for the degradation of complex plant biomass. In promising attempts to enhance the hydrolytic ability of $C$. thermocellum cellulosomes, designer cellulosomes [2-5] and reconstruction of recombinant cellulosomes [5,6] have been studied using model and natural substrates. On the other hand, $C$. thermocellum produces low levels of cellulosomes (approximately $0.1 \mathrm{~g} / \mathrm{L}$ ) compared to the high level of cellulase secretion (for example, $>1$ to $10 \mathrm{~g}$ protein/L) of Trichoderma reesei, which can produce several functionally distinct cellulase components [7]. Although C. thermocellum exhibits one of the highest observed microbial growth rates on cellulose [1], it produces less cellulase on a mass basis than aerobic microorganisms. As one promising cost-effective process to resolve these problems, consolidated bioprocessing (CBP) relies on $C$. thermocellum to ferment substrate to desired products (for example, ethanol) in one step without adding externally produced enzymes. This approach is widely recognized as the ultimate configuration for low-cost hydrolysis and fermentation of cellulosic biomass. However, intrinsic features of C. thermocellum limit its immediate and direct application to industrial ethanol fermentation from cellulose because it produces only low levels of ethanol and shows weak tolerance to ethanol [8]. In a previous study, we demonstrated remarkable improvements in cellulolytic activity of cellulosomes from the hypercellulolytic $C$. thermocellum S14 strain [9] in combination with a thermostable $\beta$ glucosidase from Thermoanaerobacter brockii (CglT) [10]. Here, we report on saccharification by $C$. thermocellum cultures supplemented with thermostable $\beta$-glucosidases, which we named biological simultaneous enzyme production and saccharification (BSES). BSES required no addition of cellulolytic enzymes. It can directly produce glucose from cellulosic materials due to supplementation of cellulosedegrading cultures with $\beta$-glucosidase. Exclusive glucose accumulation of glucose occurred when C. thermocellum was cultured with a thermostable $\beta$-glucosidase under a high cellulose load. This approach may resolve a significant barrier to economical production of bio-based chemicals and fuels from lignocellulosic biomass.

\section{Results}

Biological saccharification and glucose production using C. thermocellum cultures supplemented with CgIT

CglT of T. brockii was characterized as having not only high thermostability, but also relatively high glucose tolerance [11], which suggested it would partner well with C. thermocellum cellulosomes. We found that when C. thermocellum was cultured with CglT under a high cellulose load, cellulose was effectively converted to glucose, and a high concentration of glucose accumulated in the culture broth. Figure 1 shows the cellulose degradation rate and cellobiose and glucose concentrations in cultures grown with $100 \mathrm{~g} / \mathrm{L}$ microcrystalline cellulose. In order to allow comparison with glucose production, concentrations are reported in $\mathrm{mM}$ glucose equivalents. Based on an assumed monomer mass of $162 \mathrm{~g} / \mathrm{mol}$ of microcrystalline cellulose, the initial glucose equivalent in the cultures was $617 \mathrm{mM}$. When $C$. thermocellum was cultured alone on the medium for 10 days, the maximum consumption of cellulose was approximately $234 \mathrm{mM}$, and most cellulose remained in the broth. The glucose and cellobiose concentrations in the broth were less than $68 \mathrm{mM}$ and $37 \mathrm{mM}$, respectively, indicating that C. thermocellum cultivated on cellulose does not usually produce glucose and cellobiose in the culture broth. In contrast, when $C$. thermocellum S14 was cultured with $30 \mathrm{U} / \mathrm{g}$ CglT, it degraded all of the cellulose within 10 days. Furthermore, glucose accumulated to as high as $426 \mathrm{mM}$ in the broth. Based on the cellulose consumption, the majority (70\%) was apparently converted to glucose, implying that approximately $30 \%$ of the input cellulose was utilized in maintaining cellular homeostasis, such as for energy and

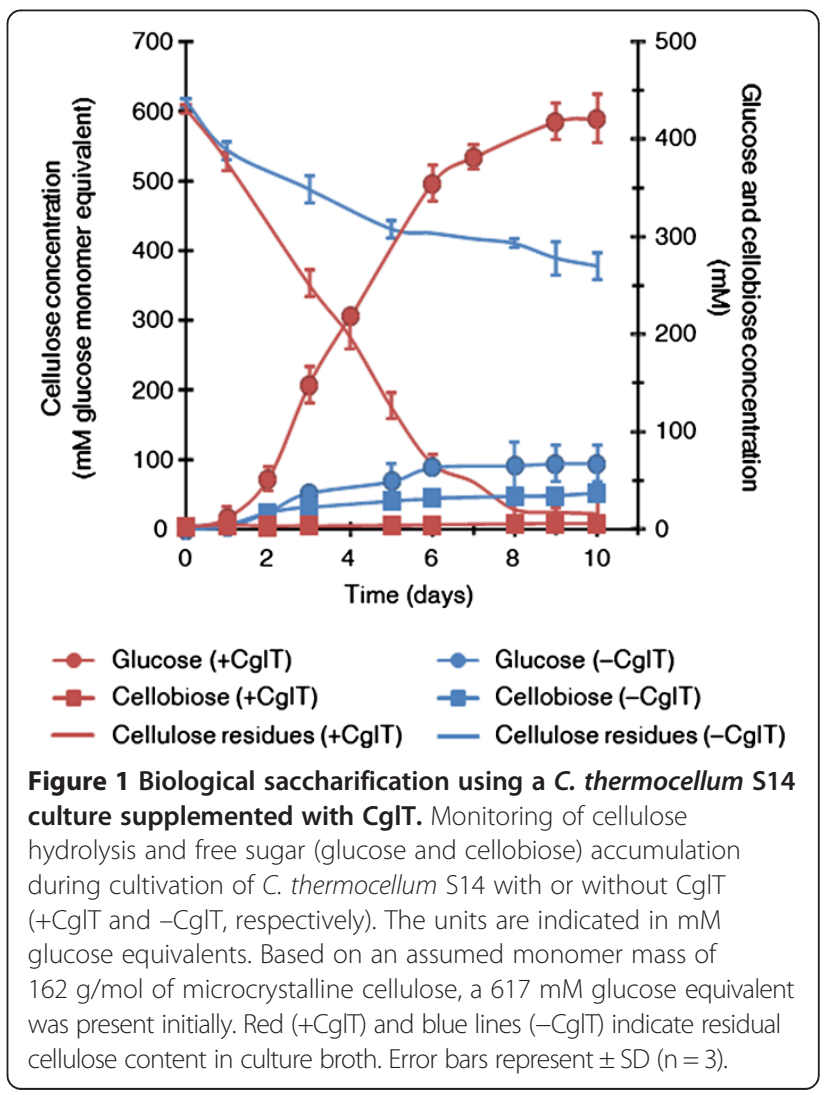


enzyme production. The cellobiose content was less than $5.9 \mathrm{mM}$ during cultivation. Cultures both with and without CglT had a $\mathrm{pH}$ range of 6.1 to 7.8 , with no $\mathrm{pH}$ control during cultivation (Figure 2). In this $\mathrm{pH}$ range, cellulosomes and CglT appeared to exhibit maximum activities for the substrate.

When cellulose degradation was facilitated by addition of CglT, the amount of free cellulosomal proteins dissociated from the cell surface was higher after 5 days. This phenomenon may be due to release of the cellulosomal proteins by solubilization of cellulose through its effective degradation. In contrast, when C. thermocellum S14 was cultured without addition of CglT, although the amount of free cellulosomal protein was slightly higher after 5 days, the majority of cellulosomal protein appeared to associate with the cellulose which still remained at over $370 \mathrm{mM}$ $(60 \mathrm{~g} / \mathrm{L})$ in the medium (Figure 2). C. thermocellum cells reportedly adhere to cellulose through cell surface anchoring proteins [8,12] and biofilms [13]. Cellulosomes are attached to the cell during early log to late exponential growth, and most are found in the medium and attached to cellulose in the stationary phase $[8,14]$. Thus, glucose production after the stationary phase may be carried out by cooperation between cellulosomes released from the cell surface and the supplemental CglT. Meanwhile, the beginning of glucose accumulation coincided with the

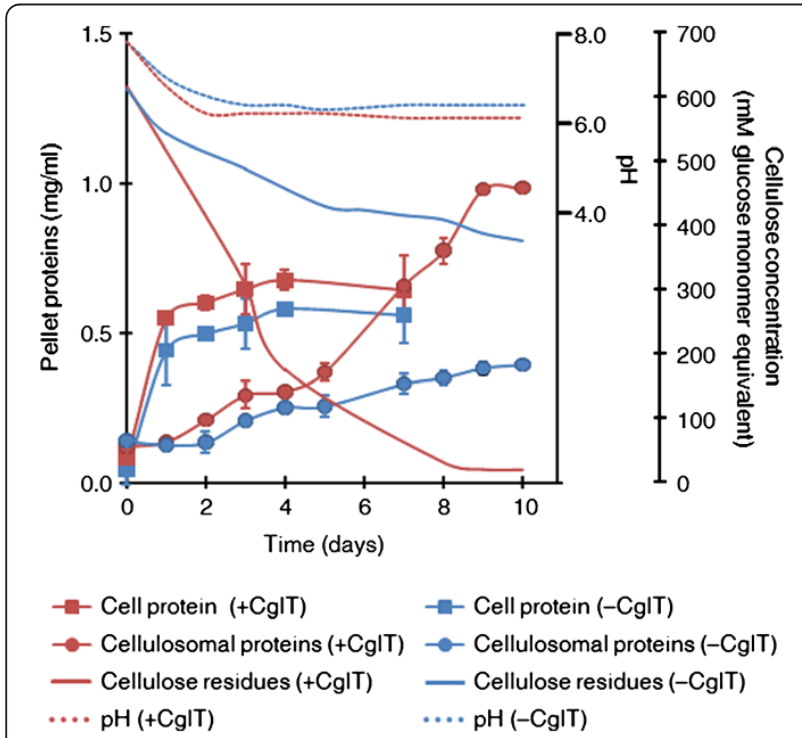

Figure 2 Profiles of $C$. thermocellum S14 cell growth and released cellulosomal protein in culture broth during biological saccharification. The protein concentration of the pellet was used as an indication of cell mass and cellulosomal protein during cultivation. C. thermocellum was cultured with or without CgIT (+CglT and - CglT, respectively) using $100 \mathrm{~g} / \mathrm{L}$ cellulose $(617 \mathrm{mM}$ glucose equivalents). The $\mathrm{pH}$ values of each culture are indicated with dotted lines. Red $(+\mathrm{Cg} / \mathrm{T})$ and blue lines $(-\mathrm{Cg} / \mathrm{T})$ indicate residual cellulose content in culture broth. Error bars represent $\pm S D(n=3)$. stage of cell growth when cells entered stationary phase (after 1 to 2 days of culturing) (Figures 1 and 2). Although the cause of the time lag for glucose accumulation is unclear, cellulosomes attached to the cell may effectively hydrolyze cellulose, allowing the cells to predominantly utilize major hydrolysates such as cellobiose and glucose for proliferation and metabolism during the early log to late exponential growth phase. When the culture reaches the stationary phase after 2 days, cellulosomes dissociated from the cell may continue to hydrolyze cellulose until it is exhausted.

\section{Optimization of biological saccharification using $C$. thermocellum cultures supplemented with CgIT}

For biological saccharification and glucose production, C. thermocellum cultures require supplementation with CglT. Alternatively, BglA (C. thermocellum) [15] and Bgl (Thermoanaerobacterium thermosaccharolyticum) [10,16], which belong to glycoside hydrolase family-1 (CarbohydrateActive enZYmes Database; http://www.cazy.org/GlycosideHydrolases.html), have been reported as other promising $\beta$-glucosidases to enhance cellulose saccharification in combination with cellulosomes. In particular, Bgl was characterized as possessing higher glucose tolerance, which may be an important property for compatibility with $C$. thermocellum cellulosomes under a high cellulose load [16]. Although there were no notable differences in $\beta$-glucosidase activity, optimum $\mathrm{pH}$, or glucose tolerance among these three $\beta$-glucosidases, the thermostability of $\mathrm{CglT}$ was significantly higher at $60^{\circ} \mathrm{C}$ (Table 1 ). To assess whether thermostability of $\beta$-glucosidases affects biological saccharification and glucose production, C. thermocellum cultures grown with $100 \mathrm{~g} / \mathrm{L}$ cellulose were supplemented with recombinant BglA or Bgl instead of CglT. Supplementation with BglA or Bgl led to lower cellulose degradation ability and glucose production than with CglT, and a higher accumulation of cellobiose was observed for both (Table 1 ). Thus, high thermostability of the $\beta$-glucosidase partnered with $C$. thermocellum was essential for efficient cellulose degradation and high glucose production. To confirm that CglT activity influences glucose production, C. thermocellum S14 cultures were supplemented with various amounts of CglT. When 10, 30, and $50 \mathrm{U}$ of CglT per g cellulose were added to the culture, the released glucose concentrations were 408, 429, and $432 \mathrm{mM}$, respectively (Figure 3A). These results suggest that maximum glucose production was achieved by supplementation of $C$. thermocellum cultures with 30 to $50 \mathrm{U}$ of $\mathrm{CglT}$ per g cellulose.

This study primarily used the originally isolated $C$. thermocellum S14 strain [9]. In order to confirm whether typical type strains of $C$. thermocellum such as ATCC 27405 and DSM 1313 also show high cellulose degradation and glucose accumulation, C. thermocellum ATCC 
Table 1 Biological saccharification using glycoside hydrolase family-1 $\beta$-glucosidases from C. thermocellum and $T$. thermosaccharolyticum

\begin{tabular}{|c|c|c|c|c|c|c|c|}
\hline & \multirow{2}{*}{$\begin{array}{l}\text { Specific } \\
\text { activity } \\
(\mathrm{U} / \mathrm{mg})\end{array}$} & \multirow{2}{*}{$\begin{array}{l}\text { Thermal } \\
\text { stability } \\
(\%)^{a}\end{array}$} & \multirow{2}{*}{$\begin{array}{l}\text { Optimum } \\
\text { temperature } \\
\left({ }^{\circ} \mathrm{C}\right)^{\mathrm{b}}\end{array}$} & \multirow{2}{*}{$\begin{array}{l}\text { Optimum } \\
\mathrm{pH}^{\mathrm{b}}\end{array}$} & \multirow{2}{*}{$\begin{array}{l}\text { Glucose } \\
\text { inhibition } \\
(\mathrm{mM})^{\mathrm{c}}\end{array}$} & \multicolumn{2}{|c|}{ Biological saccharification } \\
\hline & & & & & & $\begin{array}{l}\text { Cellobiose concentration } \\
(\mathrm{mM})^{\mathrm{d}}\end{array}$ & $\begin{array}{l}\text { Glucose concentration } \\
(\mathrm{mM})^{\mathrm{d}}\end{array}$ \\
\hline CglT (T. brockii) & $\begin{array}{c}26.0 \pm \\
0.05\end{array}$ & 97 & 60 to 75 & 6.0 to 7.0 & $450 \pm 10.2$ & $5.9 \pm 0.7$ & $425.9 \pm 24.7$ \\
\hline BgIA (C. thermocellum ATCC) & $\begin{array}{c}19.4 \pm \\
0.05\end{array}$ & 10 & 50 to 60 & 6.0 to 7.0 & $400 \pm 5.1$ & $22.1 \pm 1.3$ & $240.7 \pm 18.5$ \\
\hline $\begin{array}{l}\text { Bgl ( } T \text {. } \\
\text { thermosaccharolyticum NOl- } \\
\text { 1) }\end{array}$ & $\begin{array}{c}28.8 \pm \\
0.05\end{array}$ & 10 & 60 to 70 & 6.0 to 7.0 & $650 \pm 3.2$ & $36.4 \pm 0.7$ & $304.3 \pm 18.5$ \\
\hline
\end{tabular}

${ }^{a}$ Thermal stability is indicated as the percentage of remaining $\beta$-glucosidase activity after incubation for 24 hours at $60^{\circ} \mathrm{C}$; ${ }^{\mathrm{b}}$ range reported represents where $>90 \%$ of the maximal activity was maintained; ' glucose inhibition was calculated as the glucose concentration required to inhibit $50 \%$ of initial $\beta$-glucosidase activity; ${ }^{d}$ biological saccharification was carried out by culturing $C$. thermocellum with each $\beta$-glucosidase using $100 \mathrm{~g} / \mathrm{L}$ crystalline cellulose as described in the Methods section. To allow comparison with glucose production, cellobiose concentration was indicated in mM glucose equivalents. Values are the means of triplicate experiments \pm SD

27405 and DSM 1313 supplemented with CglT were cultured with $100 \mathrm{~g} / \mathrm{L}$ cellulose (Figure 3B). Both C. thermocellum strains could completely degrade the cellulose in medium and accumulated approximately $400 \mathrm{mM}$ glucose into the broth, indicating that biological saccharification can be applied to other $C$. thermocellum strains. Nevertheless, there were no big differences in final glucose productivity and cellulose degradation ability between these strains, though glucose accumulation during cultivation of C. thermocellum ATCC 27405 and DSM 1313 was slightly faster than that of the S14 strain (Figure 3B). Although it is unclear why moderately late glucose production is observed in C. thermocellum S14, it might be related to differences in growth properties on glucose between the S14 strain and the type strains [9]. C. thermocellum S14 can grow on glucose medium without a long lag period, suggesting that physiological responses of the S14 strain such as uptake and metabolism of glucose may differ from those of type strains.

High cellulose loading is preferred for industrial processes due to the benefits of lower capital cost and higher titers of desirable products such as ethanol. Thus, high cellulose input should provide enough fermentable sugars for ethanol production. To confirm suitable cellulose loading for biological saccharification, we investigated the relationship between saccharification ability and glucose accumulation. C. thermocellum S14 supplemented with CglT was cultured using cellulose inputs of 10, 30, 50, 100, or $150 \mathrm{~g} / \mathrm{L}$ (Figure 4). High saccharification of $86.5 \%$ to $94.6 \%$ was obtained in cultures using 10 to $100 \mathrm{~g} / \mathrm{L}$ cellulose, whereas hydrolysis decreased drastically to $51.6 \%$ when substrate input was
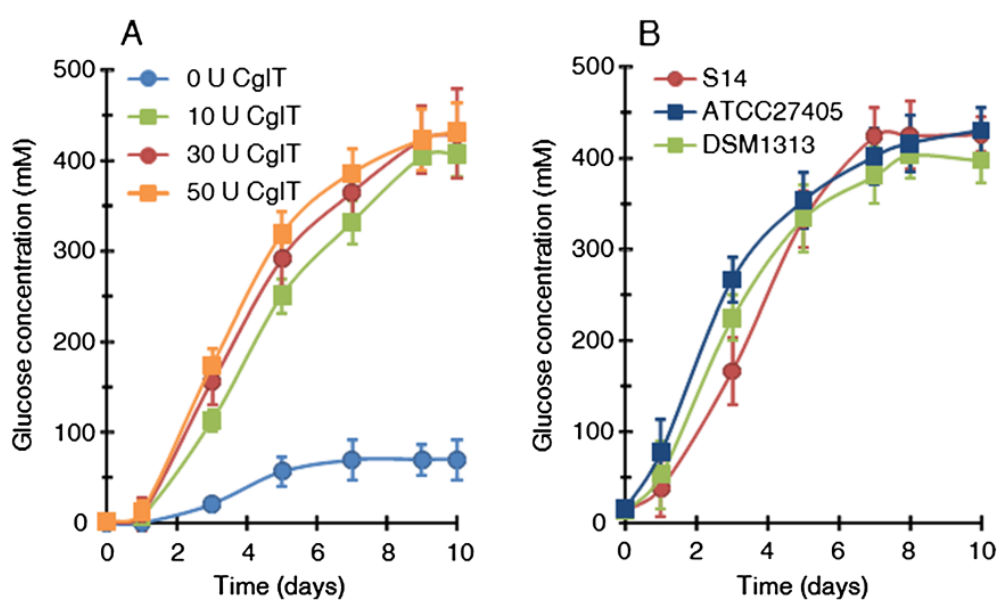

Figure 3 Optimization of biological saccharification using C. thermocellum cultures. (A) Effect of CgIT activity on biological saccharification. C. thermocellum S14 cultures were supplemented with 10, 30, or $50 \mathrm{U}$ of CgIT per g cellulose or left unsupplemented (0 U) at an initial concentration of $100 \mathrm{~g} / \mathrm{L}$ cellulose. (B) Influence of strain on glucose concentration. C. thermocellum cultures were supplemented with $30 \mathrm{U}$ of CglT per g cellulose at an initial concentration of $100 \mathrm{~g} / \mathrm{L}$ cellulose. C. thermocellum ATCC 27405 and DSM 1313 were used as type strains for comparison to the originally isolated strain S14. Error bars represent \pm SD $(n=3)$. 


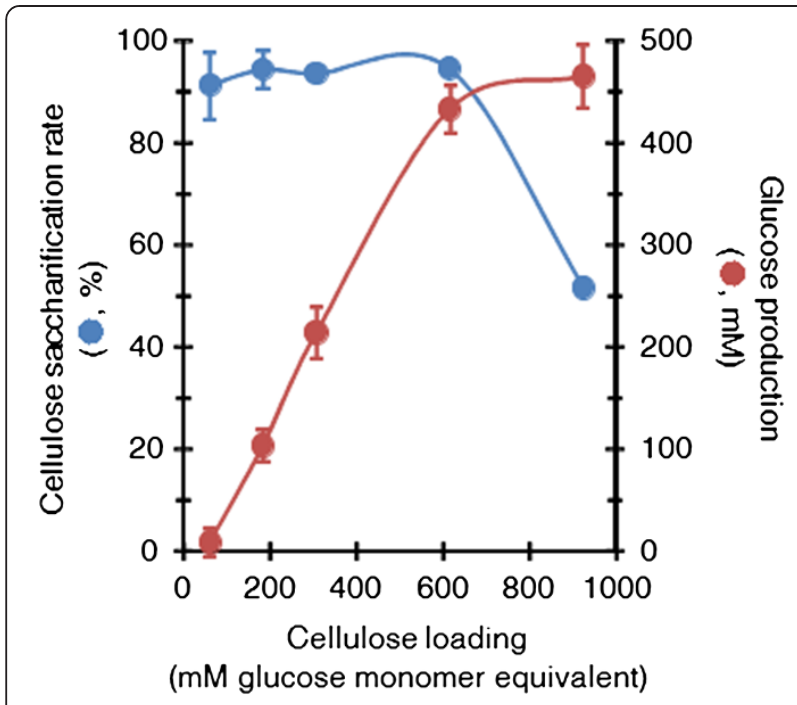

Figure 4 Relationship between cellulose saccharification ability and glucose production under various cellulose loads. Biological saccharification was carried out in BM7CO medium containing various concentrations of cellulose: $10 \mathrm{~g} / \mathrm{L}$ ( $62 \mathrm{mM}$ glucose equivalent), $30 \mathrm{~g} / \mathrm{L}$ (185 mM glucose equivalent), $50 \mathrm{~g} / \mathrm{L}$ (309 mM glucose equivalent), $100 \mathrm{~g} / \mathrm{L}$ (617 mM glucose equivalent), or $150 \mathrm{~g} / \mathrm{L}$ (926 mM glucose equivalent). The cellulose saccharification rate was calculated based on the amount of glucose released relative to the dry weight of the input cellulose, respectively. Error bars represent $\pm S D(n=3)$.

elevated to $150 \mathrm{~g} / \mathrm{L}$. The accumulation of $465 \mathrm{mM}$ glucose and $47 \mathrm{mM}$ cellobiose as hydrolysis products caused more severe end-product inhibition of cellulosomes and $\beta$-glucosidases. Cellobiose is the main product of cellulose hydrolysis by $C$. thermocellum. Johnson et al. reported complete inhibition of cellulase activity at cellobiose concentration of $20 \mathrm{~g} / \mathrm{L}$ when microcrystalline cellulose was used as the substrate [17]. C. thermocellum cellulosomes were much less sensitive to glucose, as it required $60 \mathrm{~g} / \mathrm{L}$ of glucose for $35 \%$ cellulase inhibition. To a lesser extent, glucose also inhibits C. thermocellum cellulosomes [8]. At high glucose concentration $(465 \mathrm{mM})$, the $\beta$-glucosidase activity of CglT was inhibited by $50 \%$ (Table 1 ). Fermentation products such as ethanol and acetate that accumulate during cultivation also have negative effects on hydrolysis by $C$. thermocellum [18]. In the present study ethanol concentration was $<0.3 \mathrm{~g} / \mathrm{L}$ in all cases, so ethanol is unlikely to be the cause of inhibition [19]. However, the acetate and lactate as fermentation products cause a $\mathrm{pH}$ drop in culture broth; the final $\mathrm{pH}$ values of all cultures in the present study were in the range of $\mathrm{pH} 6.1$ to 6.4 in the absence of $\mathrm{pH}$ control. These results suggested that the decreased saccharification rate in $150 \mathrm{~g} / \mathrm{L}$ cellulose might result from a performance decline of cellulosome and CglT due to high accumulation of glucose and cellobiose. On the other hand, high glucose production was obtained in cultures with a cellulose input of 30 to $150 \mathrm{~g} / \mathrm{L}$ but only $8.3 \mathrm{mM}$ from $10 \mathrm{~g} / \mathrm{L}$ (Figure 4). These results suggest that $C$. thermocellum may utilize carbon catabolism predominantly to maintain cell homeostasis, growth, and enzyme and energy production when the cellulose concentration in the culture medium is low. Thus, in order to achieve high glucose production and accumulation by biological saccharification, a cellulose load over $10 \mathrm{~g} / \mathrm{L}$ is also required in the culture medium.

\section{Biological saccharification and ethanol fermentation using alkali-treated rice straw}

To test whether biological saccharification will work for lignocellulosic biomass sources other than pure cellulose, the process was carried out using alkali-pretreated rice straw. The chemical composition of the rice straw obtained in the filtration cake (solid remaining, $47.5 \% \mathrm{w} / \mathrm{w}$ dry weight) after $10 \%(\mathrm{w} / \mathrm{v}) \mathrm{NaOH}$ pretreatment at $70^{\circ} \mathrm{C}$ for 5 days was $85.5 \pm 0.4 \%$ glucan, $5.2 \pm 0.5 \%$ xylan, $0.7 \pm$ $0.03 \%$ arabinan, and $0.3 \pm 0.09 \%$ galactan $(\mathrm{w} / \mathrm{w})$. The Klason lignin content was $6.9 \pm 0.3 \%(w / w)$, indicating a delignification ratio of $62.3 \%$ of the original lignin content $(18.3 \% \mathrm{w} / \mathrm{w})$.

C. thermocellum S14 supplemented with CglT was cultured under a high solid load of $120 \mathrm{~g} / \mathrm{L}$ alkalipretreated rice straw (3\% moisture content) containing $100 \mathrm{~g}$ glucan and $6.1 \mathrm{~g}$ xylan. Although the biomass slurry at the beginning had a high viscosity, after supplementation with CglT, viscosity was dramatically reduced. Cellobiose was maintained at a very low concentration, less than $3.9 \mathrm{mM}$ throughout cultivation. Glucose accumulated to $446 \mathrm{mM}$, corresponding to approximately $72 \%$ saccharification of input glucan, which was comparable to tests using pure cellulose (Figure 5A). Xylan in alkali-pretreated rice straw could be degraded to xylobiose and xylose, which accumulated to $28 \mathrm{mM}$ and $14 \mathrm{mM}$, respectively, as xylose equivalents. Xylan showed a high degree of hydrolysis. In profiles of sugar production, xylan degradation occurred more quickly than glucan hydrolysis, and xylobiose was released as the main product into the broth (Figure 5A). A xylan structural barrier is one of the major mechanisms that limits the accessibility of cellulases to the cellulose; cellulose accessibility is necessary for synergistic cooperation between xylanases and cellulases [20]. The released xylobiose and xylose remained in the culture supernatant because $C$. thermocellum is unable to utilize pentose sugars [8].

In order to evaluate whether the hydrolysis slurry derived from biological saccharification could be immediately used for ethanol fermentation, Saccharomyces cerevisiae was directly inoculated to the slurry. No other nutrients were added. The slurry (pH 5.9) contained $446 \mathrm{mM}$ of glucose, C. thermocellum cells, and CglT, as well as fermentation 

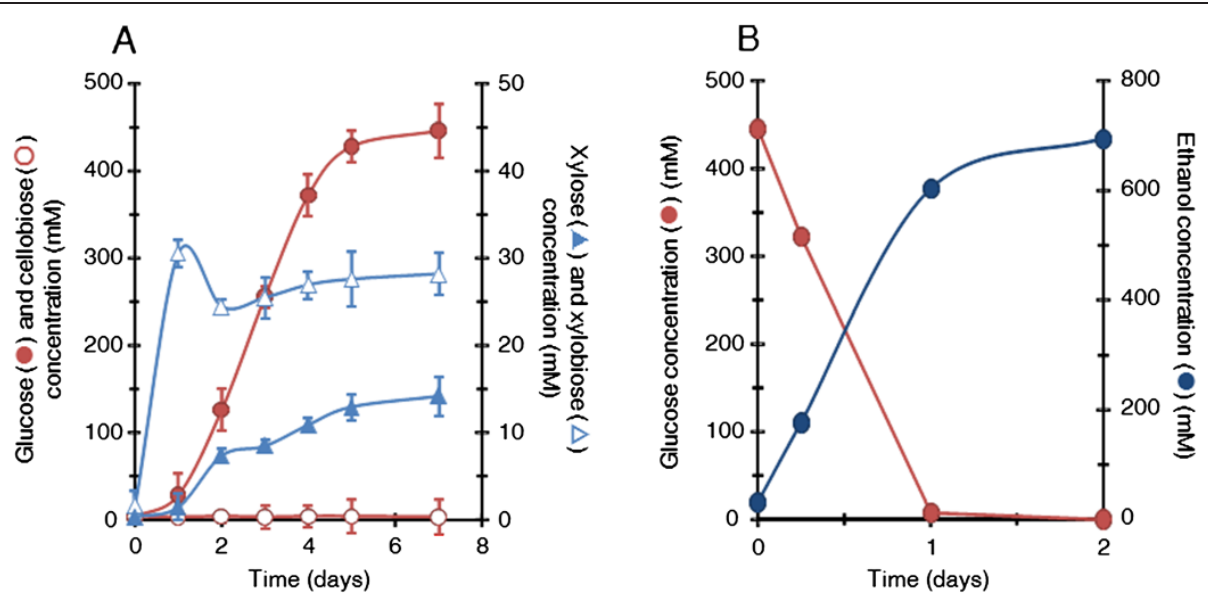

Figure 5 Biological saccharification and ethanol fermentation profiles using alkali-pretreated rice straw. (A) Saccharification and (B) fermentation. The units are given in $\mathrm{mM}$ glucose and xylose equivalents. Initially, based on an assumed monomer mass of $162 \mathrm{~g} / \mathrm{mol}$ of glucan and $132 \mathrm{~g} / \mathrm{mol}$ of xylan, $617 \mathrm{mM}$ glucose and $46 \mathrm{mM}$ xylan equivalents were present. Error bars represent $\pm \mathrm{SD}(\mathrm{n}=3)$.

products such as lactic acid $(2.15 \pm 0.02 \mathrm{mg} / \mathrm{mL})$, acetic acid $(4.18 \pm 0.07 \mathrm{mg} / \mathrm{mL})$, and ethanol $(0.13 \pm 0.02 \mathrm{mg} / \mathrm{mL})$. Fermentation profiles of ethanol production and glucose consumption were obtained from the slurry (Figure 5B), as well as profiles of cultures grown on the reference fermentation test using medium containing the same concentration of glucose. Ethanol productivity was $695 \pm 4 \mathrm{mM}$, which corresponds to approximately $85 \%$ of the theoretical yield, indicating that the slurry obtained from $C$. thermocellum cultures supplemented with CglT can be fermented directly without any inhibition.

\section{Discussion}

Here we describe the first example of biological saccharification with glucose production from lignocellulosic biomass. To achieve this, we used C. thermocellum cultures supplemented with a thermostable $\beta$-glucosidase. Biological saccharification using $C$. thermocellum requires no addition of cellulase or hemicellulase; however, supplementation with a thermostable $\beta$-glucosidase to the culture is essential for glucose accumulation. We named this saccharification process BSES. Although BSES is similar to CBP in whole-cell catalyzing systems using $C$. thermocellum, it focuses on the objective of hydrolysis of lignocellulosic biomass and glucose production. Thus, BSES can be imagined as combining the two processing steps of cellulase production and cellulose hydrolysis, which are ordinarily performed as separate hydrolysis and fermentation (SHF) reactions into a single step [1].

It is known that a combination of cellulosomes and a thermostable $\beta$-glucosidase leads to efficient saccharification due to elimination of end-product inhibition under high cellulose loading $[10,15,21]$. At the same time, the $C$. thermocellum cellulase complex is substantially more effective during microbial hydrolysis than purified cellulase preparations from this microorganism [22]. This phenomenon, called enzyme-microbe synergy, requires the presence of metabolically active cellulolytic microbes, suggesting that the process may require not only the removal of hydrolysis products from the fermentation broth, but also surface phenomena involving adherent cellulolytic microorganisms [22]. Thus, the efficient saccharification and glucose accumulation through BSES may be caused by enzyme-microbe synergy and efficient elimination of end-product inhibition by cellobiose in the fermentation broth with CglT.

C. thermocellum has an uptake system capable of assimilating cellodextrins, which are released through simultaneous multiple hydrolysis steps mediated by adjacent cellulosomal subunits [14]. Glucose uptake occurs only in cells grown on the monomer and has been characterized as a low-affinity system compared to the one involved in cellobiose uptake [23]. Growth of C. thermocellum ATCC 27405 on glucose was obtained only after an exceptionally long lag of over 100 hours [24], and the cell yield was higher on cellobiose than on glucose [25]. The physiological responses and adaptation related to the long lag period of C. thermocellum for utilization of monosaccharides such as glucose are understood as the lack of any beneficial availability of ATP derived from phosphorolytic cleavage by intracellular cellobiose phosphorylase $(\mathrm{CbP})$ and cellodextrin phosphorylase (CdP) during growth on glucose $[1,26]$, and the requirement for induction or deregulation of the utilization pathways involving glucose uptake $[1,8]$. Thus, the phenomenon of high glucose accumulation appears to be due not only to effective cellulose degradation by cooperation of cellulosomes and CglT, but also to a low-affinity system for glucose uptake by C. thermocellum. The phenomenon of high glucose 
accumulation may also be found in BSES using mesophilic cellulolytic anaerobes possessing similar uptake and phosphorylation ( $\mathrm{CbP}$ and $\mathrm{CdP}$ ) systems that are known to be widely distributed in cellulose-utilizing anaerobes, such as C. cellulovorans [5,27], C. cellulolyticum [28], and Ruminococcus flavefaciens [29]. On the other hand, C. thermocellum may be better suited for BSES than the mesophilic anaerobes for the following reasons: (1) C. thermocellum exhibits substantially higher enzyme production levels and growth rates on crystalline cellulose than any mesophiles [1,30]; (2) thermophiles, including C. thermocellum, are considered to be robust microorganisms and the cellulolytic enzymes are stable in thermophilic conditions [31]; (3) the problem of contamination in the presence of high glucose concentrations can be avoided in the growth condition for C. thermocellum [8]; and (4) C. thermocellum can degrade hemicellulose as well as mesophiles [32-34], but does not utilize pentose sugars, such as xylose and xylobiose.

One method that may reduce the amount of cellulase used and increase enzymatic productivity is recycling of the cellulases. Many studies have already been carried out on recycling strategies using $T$. reesei cellulases [35]. Cellulase recycling approaches have included recovery of free enzymes from the liquid fraction [36] and introduction of fresh substrate to the liquor fraction, allowing the enzymes to be absorbed to the substrate before separation and hydrolysis [37]. Recently, we developed a recycling method utilizing a combination of $C$. thermocellum cellulosomes and chimeric CBM-CglT created by fusing the carbohydrate-binding module CBM3 from the scaffolding protein CipA into the $\mathrm{N}$-terminal region of CglT [38]. It seems that the concept of recycling an enzyme may easily apply to biological saccharification using $C$. thermocellum and CglT. If CBM-CglT instead of CglT is used during biological saccharification, hydrolysis and glucose production would be carried out for several days, after which cellulosomes, CBM-CglT, and insoluble solid residues bound to $C$. thermocellum cells may be recovered by adding fresh pretreated rice straw to the broth. C. thermocellum and CBM-CglT would only be expected to be added during the first round, making additional $\beta$-glucosidase or fresh inoculum unnecessary (Figure 6). CglT and CBM-CglT appeared to be suitable enzymes, since both recombinant proteins can be highly expressed as soluble proteins in the periplasmic space of Escherichia coli ( $>14,500 \mathrm{U} / \mathrm{L}$ medium) and simply prepared by direct heat treatment $\left(65^{\circ} \mathrm{C}\right)$ and cell lysis $[39,40]$. Alternatively, a C. thermocellum expressible BglA was created in shuttle vector pIBglA in an attempt to increase cellulase activity [41]. When these ideas can be introduced to a system for biological saccharification of lignocellulosic biomass, the most cost-effective saccharification system not requiring any enzymes can be established.

\section{Conclusions}

Economical production of bio-based chemicals and fuels from lignocellulosic biomass by enzymatic means continues to require considerable research in terms of both technical and economic aspects. In particular, cellulolytic enzymes continue to be one of the major problems associated with the hydrolysis process. C. thermocellum is the most potent cellulose-degrading bacterium known to produce cellulosomes. Biological saccharification using C. thermocellum cultures supplemented with thermostable

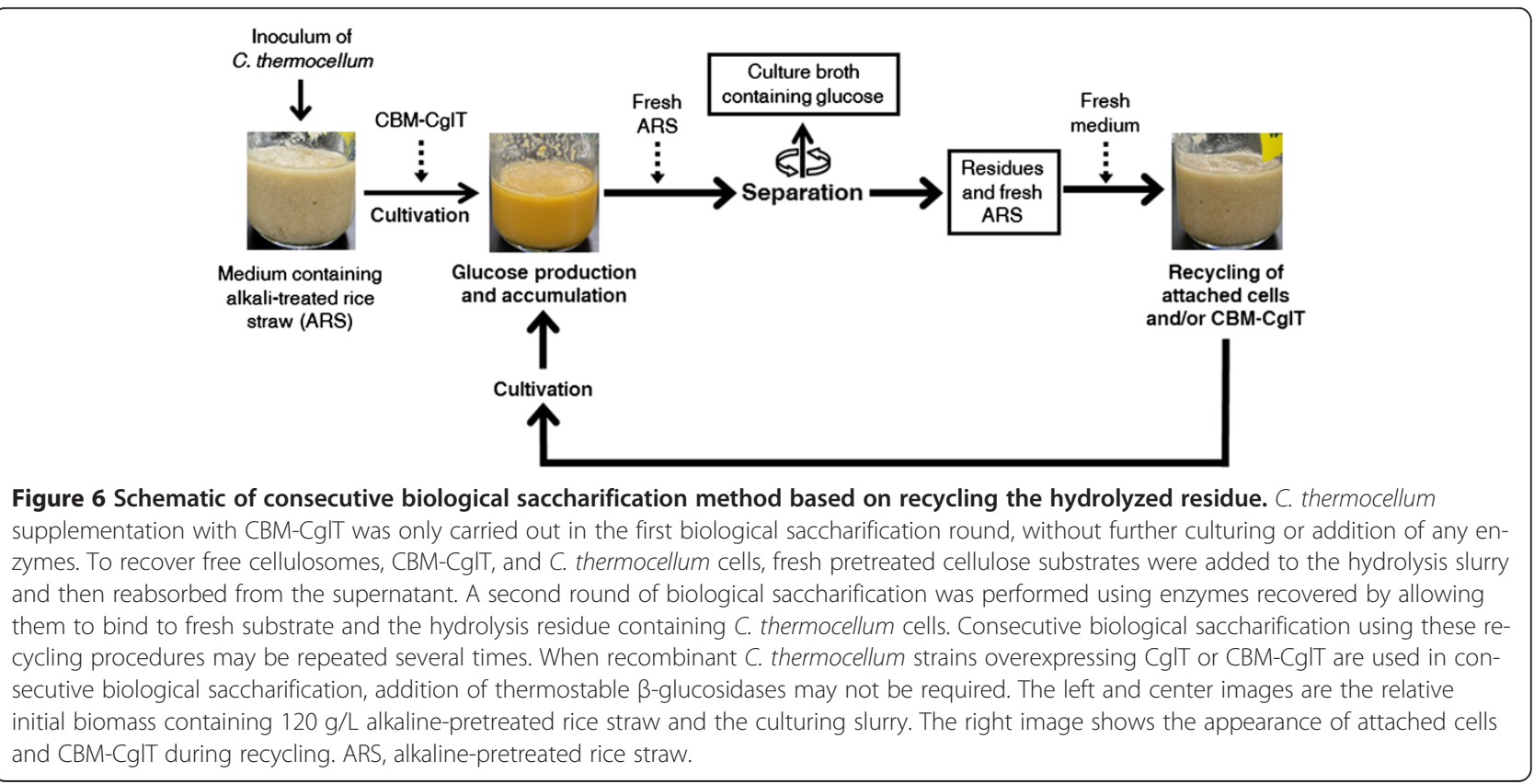


$\beta$-glucosidases provide a platform for production of fermentable sugars with drastically reduced requirements for enzyme amounts. This advance is expected to immediately benefit for biomass refinery. To take full advantage of these prospects, future studies will address improvement of $C$. thermocellum, the cellulase system, and thermostable $\beta$-glucosidases. The goals are much higher tolerance to glucose, cellobiose, and fermentation products such as ethanol and acetate.

\section{Methods}

\section{Organisms, media, and growth conditions}

The hypercellulolytic strain C. thermocellum S14 has been deposited with the National Institute of Technology and Evaluation Patent Microorganisms Depositary (NPMD; Chiba, Japan) as NITE P-627. C. thermocellum ATCC 27405 and T. brockii ATCC 33075 were obtained from the American Type Culture Collection (ATCC; Manassas, VA, USA). C. thermocellum DSM 1313 was obtained from Leibniz Institute DSMZ - German Collection of Microorganisms and Cell Cultures (Braunschweig, Germany). T. thermosaccharolyticum NOI-1 was originally isolated from soil and stored in our laboratory [42]. C. thermocellum was grown on BM7CO medium $[9,43]$ supplemented with $10 \mathrm{~g} / \mathrm{L}$ microcrystalline cellulose powder (Sigmacell type 20; Sigma-Aldrich, St Louis, MO, USA) or 10 g/L cellobiose (Sigma-Aldrich). T. brockii was grown in modified DSMZ 122 medium supplemented with $5 \mathrm{~g} / \mathrm{L}$ cellobiose as the carbon source [10]. All BM7CO media were degassed in boiling water and bubbled with high purity carbon dioxide gas. E. coli DH5 $\alpha$ (Takara Bio, Shiga, Japan), E. coli BL21(DE3), and plasmid pET19b (Merck KGaA, Darmstadt, Germany) served as the cloning host, expression host, and vector, respectively. E. coli cells were grown at $37^{\circ} \mathrm{C}$ in Luria-Bertani medium containing ampicillin $(50 \mu \mathrm{g} / \mathrm{mL})$. The sake-brewing yeast $S$. cerevisiae Kyokai no. 3 (K3) was obtained from the National Research Institute of Brewing (NRIB; Hiroshima, Japan). In preculture, the yeast was grown aerobically in static culture at $30^{\circ} \mathrm{C}$ on complete medium (YPD) containing $20 \mathrm{~g} / \mathrm{L}$ peptone, $10 \mathrm{~g} / \mathrm{L}$ yeast extract (Difco Laboratories, Detroit, MI, USA), and $20 \mathrm{~g} / \mathrm{L}$ glucose.

\section{Preparation of recombinant $\beta$-glucosidases}

Preparation of chromosomal and plasmid DNA, and transformation were carried out by standard procedures or according to supplier protocols (Qiagen, Frederick, MD, USA). Constructed plasmid pET19CglT was used to prepare recombinant CgIT [10]. We designed oligonucleotide primers to clone $b g l \mathrm{~A}$ from $C$. thermocellum and $b g l$ from T. thermosaccharolyticum NOI-1. Primer pairs containing artificial restriction enzyme recognition sites (italics) were used to amplify fragments of bglA (5'-ATG CTCGAGATGTTTCCTCTAGGTTATAAT-3' for sense primer with XhoI sites, and 5'-ATTGCTCAGCTTAAAA ACCGTTGTTTTTGA-3' for antisense primer with Bpu1102 sites) from C. thermocellum ATCC 27405 and bgl (5'-GGAATTCCATATG TCGGACTTTAACAAGG A-3' for sense primer with NdeI sites, and AGTCACTC GAGAATGGTCCTAGTGGAAAT-3' for antisense primer with XhoI) from $T$. thermosaccharolyticum NOI-1 by PCR using genomic DNA as template. PCR was performed with PrimeSTAR HS DNA polymerase (Takara Bio) under standard conditions according to the manufacturer's instructions. The amplified fragments for $b g l \mathrm{~A}$ and $b g l$ were respectively inserted between the XhoI and Bpu1102 sites and the NdeI and XhoI sites of pET19b to generate pET19BglA and pET19Bgl. Expressed CglT, BglA, and Bgl were purified by nickel affinity column chromatography using Ni-NTA agarose resins and desalted using a desalting column.

\section{Enzyme and protein assays}

Assays for crude and recombinant $\beta$-glucosidase were performed at $60^{\circ} \mathrm{C}$ in $0.1 \mathrm{M}$ sodium acetate buffer (pH 6.0) with $5 \mathrm{mM} \mathrm{CaCl} 2$ under static conditions for 10 minutes [10]. Determination of $\beta$-glucosidase activity was based on measurement of the release of $p$-nitrophenol from $p$-nitrophenyl $\beta$-D-glucoside. One unit of enzyme releases $1 \mu \mathrm{mol}$ equivalent of $p$-nitrophenol per minute. All protein concentrations were determined using the Pierce BCA assay kit (Thermo Fisher Scientific, Waltham, MA, USA) with BSA as the standard.

\section{Estimation of cellulosomes and cellular protein for monitoring cell growth}

Cell growth in BM7CO supplemented with cellulose was monitored based on the increase in the pellet protein concentration. Briefly, cells were lysed in a $\mathrm{NaOH} / \mathrm{SDS}$ solution of $0.2 \mathrm{~N} \mathrm{NaOH}$ (Wako Pure Chemical, Osaka, Japan) containing $0.2 \%(\mathrm{w} / \mathrm{v})$ sodium dodecyl sulfate (SDS; Wako Pure Chemical). Cell debris and residual solids were pelleted from the $\mathrm{NaOH} / \mathrm{SDS}$ solution and removed by centrifugation $(9,700 \times g$ for 5 minutes), and the protein concentration in the supernatant was estimated using the Pierce BCA assay kit. Cellulosomes in cell-free broth were isolated from fermenting cultures using the affinity digestion method [44], which is based on binding of cellulosomes to amorphous cellulose. Although over $90 \%$ of cellulase activity in the crude supernatant can be recovered by this method, the purified cellulosomal proteins included not only cellulosomes but also non-cellulosomal proteins that can be adsorbed by the amorphous cellulose. Cultures of $1 \mathrm{~mL}$ were centrifuged and the cell-free broth was incubated with phosphoric acid-swollen cellulose (PASC; $100 \mu \mathrm{g} / \mathrm{mL}$ of cell-free broth) overnight at $4^{\circ} \mathrm{C}$ to obtain cellulosomes bound to the cellulose. On the following day, the 
amorphous cellulose with bound enzymes was centrifuged and washed twice with $50 \mathrm{mM}$ sodium phosphate buffer ( $\mathrm{pH}$ 7.0). The pellets were resuspended in $1 \mathrm{~mL}$ $\mathrm{NaOH} / \mathrm{SDS}$. The total protein concentration of the isolated cellulosome samples was determined with the BCA assay kit.

\section{Biological saccharification using $C$. thermocellum cultures supplemented with $\beta$-glucosidases}

For subculturing, part of a $C$. thermocellum stock culture was inoculated by syringe into $50 \mathrm{~mL}$ of BM7CO medium containing $10 \mathrm{~g} / \mathrm{L}$ microcrystalline cellulose powder. The subculture was incubated at $60^{\circ} \mathrm{C}$ for 2 days with rotary shaking at $130 \mathrm{rpm}$. The subculture was inoculated again by syringe into $50 \mathrm{~mL}$ fresh BM7CO medium containing $100 \mathrm{~g} / \mathrm{L}$ microcrystalline cellulose or $120 \mathrm{~g} / \mathrm{L}$ (100 g/L glucan equivalent) alkali-pretreated rice straw as the sole carbon sources. After incubation at $60^{\circ} \mathrm{C}$ for 6 hours with rotary shaking, the cultures were directly supplemented with $30 \mathrm{U} / \mathrm{g}$ cellulose or glucan of $\beta$-glucosidase (CglT, $\mathrm{BglA}$, or Bgl; 0.03 to $0.05 \mathrm{mg}$ protein/U) in an anaerobic chamber (Hirasawa Co., Ltd. Tokyo, Japan) with a $\mathrm{CO}_{2}$ based mixed gas atmosphere. Cultures containing $\beta$ glucosidase were incubated again at $60^{\circ} \mathrm{C}$ for 10 days with rotary shaking at $130 \mathrm{rpm}$. The concentration of the released sugar was measured by HPLC using culture supernatants obtained by centrifugation $\left(9,700 \times g, 4^{\circ} \mathrm{C}\right.$ for 5 minutes). To measure cellulose and glucan concentration in the hydrolyzed residues, aliquots of the separated pellets were dried overnight at $70^{\circ} \mathrm{C}$ to calculate the percentage of remaining cellulose and the glucan concentration by measuring the weight or following the National Renewable Energy Laboratory (NREL; Golden, CO, USA) chemical analysis procedure described below.

\section{Compositional analysis of untreated and treated rice straw}

The chemical composition of oven-dried natural and alkalitreated rice straw was analyzed following the NREL chemical analysis and testing standard procedure (http://www. nrel.gov/biomass/analytical_procedures.html). Each sample was hydrolyzed with $72 \%$ sulfuric acid at $30^{\circ} \mathrm{C}$ for 60 minutes, followed by $3 \%$ sulfuric acid at $121^{\circ} \mathrm{C}$ for $60 \mathrm{mi}-$ nutes. The autoclaved hydrolyzed solution was neutralized to $\mathrm{pH} 6.0$ with calcium carbonate and vacuum-filtered through a filtering crucible. Mono- and oligosaccharide components were separated on an Aminex HPX-87H column (Bio-Rad Laboratories, Hercules, CA, USA) by HPLC with $1 \mathrm{mM}$ sulfuric acid at a flow rate of $0.6 \mathrm{~mL} / \mathrm{min}$ on a Prominence instrument (Shimadzu Corp., Kyoto, Japan) operated at $60^{\circ} \mathrm{C}$ and equipped with a Shimadzu RID-10A refractive index detector. Acid insoluble lignin (Klason lignin) content was defined as the weight of the filter cake (oven-dried at $70^{\circ} \mathrm{C}$ to constant weight).

\section{Preparation of alkali-pretreated rice straw}

Rice straw (glucan $40.6 \pm 0.5 \%$, xylan $17.6 \pm 0.1 \%$, arabinan $4.7 \pm 0.1 \%$, galactan $3.4 \pm 0.1 \%$, and Klason lignin $18.3 \pm 0.1 \%$ ) was purchased from Miyahara (Nagano, Japan). Rice straw was ground through a $0.5 \mathrm{~mm}$ mesh screen (ZM-100; Retsch, Haan, Germany) and $30 \mathrm{~g}$ of the substrate was added to a $300 \mathrm{~mL}$ autoclavable bottle with $150 \mathrm{~mL}$ of $10 \%(\mathrm{w} / \mathrm{v}) \mathrm{NaOH}$ solution. The bottle was incubated for 5 days at $70^{\circ} \mathrm{C}$. The slurry was filtered through a disposable non-woven filter to recover the insoluble solids. The solids were washed with distilled water until the $\mathrm{pH}$ of the solid became neutral. The washed solids were dried in an oven at $60^{\circ} \mathrm{C}$ for 96 hours. After drying, the moisture content of the samples was measured.

\section{Fermentation tests}

The cultures were directly fermented by addition of yeast without any supplements. BM7CO medium adjusted to $\mathrm{pH} 7.0$ with an $\mathrm{HCl}$ solution (containing the same concentration of glucose) was inoculated with yeast to obtain the fermentation profile as a reference fermentation test. S. cerevisiae strain K3 precultured on YPD medium was washed twice with sterilized water and inoculated into each medium at $5 \%(\mathrm{v} / \mathrm{v})$ and incubated at $30^{\circ} \mathrm{C}$. Samples were analyzed for ethanol using a model GC-2014 gas chromatograph (Shimadzu) with a flame ionization detector (FID).

\section{Abbreviations}

ARS: alkaline-treated rice straw; ATCC: American Type Culture Collection; BSA: bovine serum albumin; BSES: biological simultaneous enzyme production and saccharification; CBM: carbohydrate-binding module; CBM-CglT: Chimera $\beta$-glucosidase fused CBM3 from the scaffolding protein CipA into the N-terminal region of CgIT; CBP: consolidated bioprocessing; CbP: cellobiose phosphorylase; CdP: cellodextrin phosphorylase; FID: flame ionization detector; HPLC: high-performance liquid chromatography; NPMD: National Institute of Technology and Evaluation Patent Microorganisms Depositary; NREL: National Renewable Energy Laboratory; NRIB: National Research Institute of Brewing; PASC: phosphoric acid-swollen cellulose; PCR: polymerase chain reaction; SD: standard deviation;

SDS: sodium dodecyl sulfate; SHF: separate hydrolysis and fermentation; YPD: yeast extract peptone dextrose.

\section{Competing interests}

The authors declare that they have no competing interests.

\section{Authors' contributions}

PPra carried out the cultivation, collected HPLC data, and helped in the design and interpretation of the experiments. RW helped carry out enzyme assays and participated in the design and interpretation of experiments, and in design and construction of the vectors. $C T, P P a, K R, L D, J S$, and $K S$ assisted in the design, interpretation, and coordination of the experiments and edited the manuscript. YM helped to draft the manuscript. AK conceived of the project, assisted in the design and interpretation of experiments, and helped to draft and edit the manuscript. All authors read and approved the final manuscript.

\section{Acknowledgments}

This work was conducted as part of a research project funded by a grant (Development of Technologies for Biofuel Production Systems in Rural Areas) from the Ministry of Agriculture, Forestry and Fisheries of Japan. 


\section{Author details}

'Biological Resources and Post-harvest Division, Japan International Research Center for Agricultural Sciences (JIRCAS), 1-1 Ohwashi, Tsukuba, Ibaraki 305-8686, Japan. ${ }^{2}$ Pilot Plant Development and Training Institute (PDTI), King Mongkut's University of Technology Thonburi (KMUTT), Bangkok, Thailand. ${ }^{3}$ School of Bioresources and Technology, King Mongkut's University of Technology Thonburi (KMUTT), Bangkok, Thailand. ${ }^{4}$ University of Tsukuba Graduate School of Life and Environmental Sciences, 1-1-1 Ten-noudai, Tsukuba, Ibaraki 305-8572, Japan.

Received: 2 October 2013 Accepted: 5 December 2013 Published: 21 December 2013

\section{References}

1. Lynd L, Weimer P, Van Zyl W, Pretorius I: Microbial cellulose utilization: fundamentals and biotechnology. Microbiol Mol Biol Rev 2002, 66:506-577.

2. Bayer E, Belaich J, Shoham Y, Lamed R: The cellulosomes: multienzyme machines for degradation of plant cell wall polysaccharides. Annu Rev Microbiol 2004, 58:521-554.

3. Moraïs S, Barak Y, Caspi J, Hadar Y, Lamed R, Shoham Y, Wilson DB, Bayer EA: Cellulase-xylanase synergy in designer cellulosomes for enhanced degradation of a complex cellulosic substrate. MBio 2010, 1. doi:10.1128/ mBio.00285-10.

4. Bayer EA, Morag E, Lamed R: The cellulosome-a treasure-trove for biotechnology. Trends Biotechnol 1994, 12:379-386.

5. Doi RH, Kosugi A: Cellulosomes: plant-cell-wall-degrading enzyme complexes. Nat Rev Micro 2004, 2:541-551.

6. Krauss J, Zverlov W, Schwarz WH: In vitro reconstitution of the complete Clostridium thermocellum cellulosome and synergistic activity on crystalline cellulose. Appl Environ Microbiol 2012, 78:4301-4307.

7. You C, Zhang X-Z, Sathitsuksanoh N, Lynd LR, Zhang Y-HP: Enhanced microbial utilization of recalcitrant cellulose by an ex vivo cellulosomemicrobe complex. Appl Environ Microbiol 2012, 78:1437-1444.

8. Demain A, Newcomb M, Wu J: Cellulase, clostridia, and ethanol. Microbiol Mol Biol Rev 2005, 69:124-154.

9. Tachaapaikoon C, Kosugi A, Pason P, Waeonukul R, Ratanakhanokchai K, Kyu $K$, Arai T, Murata $Y$, Mori $Y$ : Isolation and characterization of a new cellulosome-producing Clostridium thermocellum strain. Biodegradation 2012, 23:57-68.

10. Waeonukul R, Kosugi A, Tachaapaikoon C, Pason P, Ratanakhanokchai K, Prawitwong $P$, Deng $L$, Saito M, Mori Y: Efficient saccharification of ammonia soaked rice straw by combination of Clostridium thermocellum cellulosome and Thermoanaerobacter brockii $\beta$-glucosidase. Bioresour Technol 2012, 107:352-357.

11. Breves R, Bronnenmeier K, Wild N, Lottspeich F, Staudenbauer WL, Hofemeister J: Genes encoding two different beta-glucosidases of Thermoanaerobacter brockii are clustered in a common operon. Appl Environ Microbiol 1997, 63:3902-3910.

12. Fujino T, Béguin P, Aubert JP: Organization of a Clostridium thermocellum gene cluster encoding the cellulosomal scaffolding protein CipA and a protein possibly involved in attachment of the cellulosome to the cell surface. J Bacteriol 1993, 175:1891-1899.

13. Dumitrache A, Wolfaardt G, Allen G, Liss SN, Lynd LR: Form and function of Clostridium thermocellum biofilms. Appl Environ Microbiol 2013, 79:231-239.

14. Mayer F, Coughlan MP, Mori Y, Ljungdahl LG: Macromolecular organization of the cellulolytic enzyme complex of Clostridium thermocellum as revealed by electron microscopy. Appl Environ Microbiol 1987, 53:2785-2792

15. Gefen G, Anbar M, Morag E, Lamed R, Bayer EA: Enhanced cellulose degradation by targeted integration of a cohesin-fused $\beta$-glucosidase into the Clostridium thermocellum cellulosome. Proc Natl Acad Sci USA 2012, 109:10298-10303.

16. Pei J, Pang Q, Zhao L, Fan S, Shi H: Thermoanaerobacterium thermosaccharolyticum beta-glucosidase: a glucose-tolerant enzyme with high specific activity for cellobiose. Biotechnol Biofuels 2012, 5:31

17. Johnson EA, Reese ET, Demain AL: Inhibition of Clostridium thermocellum cellulase by end products of celluloysis. J Appl Biochem 1982, 4:64-71.

18. Chinn M, Nokes S, Strobel H: Influence of process conditions on end product formation from Clostridium thermocellum 27405 in solid substrate cultivation on paper pulp sludge. Bioresour Technol 2007, 98:2184-2193
19. $X u$ C, Qin $Y, L i Y, J i Y$, Huang J, Song $H, X u J$ J: Factors influencing cellulosome activity in consolidated bioprocessing of cellulosic ethanol. Bioresour Technol 2010, 101:9560-9569.

20. Hu J, Arantes V, Saddler J: The enhancement of enzymatic hydrolysis of lignocellulosic substrates by the addition of accessory enzymes such as xylanase: is it an additive or synergistic effect? Biotech Biofuels 2011, 4:36.

21. Lamed R, Kenig R, Morgenstern E, Calzada J, Micheo F, Bayer E: Efficient cellulose solubilization by a combined cellulosome- $\beta$-glucosidase system. Appl Biochem Biotechnol 1991, 27:173-183.

22. Lu Y, Zhang Y-HP, Lynd LR: Enzyme-microbe synergy during cellulose hydrolysis by Clostridium thermocellum. Proc Natl Acad Sci USA 2006, 103:16165-16169.

23. Strobel H, Caldwell F, Dawson K: Carbohydrate transport by the anaerobic thermophile Clostridium thermocellum LQRI. Appl Environ Microbiol 1995, 61:4012-4015.

24. Johnson EA, Bouchot F, Demain AL: Regulation of cellulase formation in Clostridium thermocellum. J Gen Microbiol 1985, 131:2303-2308.

25. Strobel H: Growth of the thermophilic bacterium Clostridium thermocellum on continuous culture. Curr Microbiol 1995, 31:210-214.

26. Zhang Y, Lynd L: Cellulose utilization by Clostridium thermocellum: bioenergetics and hydrolysis product assimilation. Proc Natl Acad SC USA 2005, 102:7321-7325.

27. Doi RH: Cellulases of mesophilic microorganisms. Ann N Y Acad Sci 2008, $1125: 267-279$

28. Fierobe H-P, Pagès $S$, Bélaïch $A$, Champ $S$, Lexa $D$, Bélaïch J-P: Cellulosome from Clostridium cellulolyticum: molecular study of the dockerin/cohesin interaction. Biochemistry 1999, 38:12822-12832.

29. Ding S-Y, Rincon MT, Lamed R, Martin JC, McCrae SI, Aurilia V, Shoham Y, Bayer EA, Flint HJ: Cellulosomal scaffoldin-like proteins from Ruminococcus flavefaciens. J Bacteriol 2001, 183:1945-1953.

30. Lynd $L R$, Grethlein HE, Wolkin RH: Fermentation of cellulosic substrates in batch and continuous culture by Clostridium thermocellum. Appl Environ Microbiol 1989, 55:3131-3139.

31. Turner P, Mamo G, Karlsson E: Potential and utilization of thermophiles and thermostable enzymes in biorefining. Microb Cell Fact 2007, 6:9.

32. Mohand-Oussaid O, Payot S, Guedon E, Gelhaye E, Youyou A, Petitdemange $H:$ The extracellular xylan degradative system in Clostridium cellulolyticum cultivated on xylan: evidence for cell-free cellulosome production. J Bacteriol 1999, 181:4035-4040

33. Vodovnik M, Duncan SH, Reid MD, Cantlay L, Turner K, Parkhill J, Lamed R, Yeoman CJ, Miller MEB, White BA, Bayer EA, Marinšek-Logar R, Flint HJ: Expression of cellulosome components and type IV pili within the extracellular proteome of Ruminococcus flavefaciens 007. PLoS One 2013, 8:e65333.

34. Matsui K, Bae J, Esaka K, Morisaka H, Kuroda K, Ueda M: Exoproteome profiles of Clostridium cellulovorans on various carbon sources. Appl Environ Microbiol 2013, 79:6576-6584.

35. Ramos LP, Breuil C, Saddler JN: The use of enzyme recycling and the influence of sugar accumulation on cellulose hydrolysis by Trichoderma cellulases. Enzyme Microb Technol 1993, 15:19-25.

36. Tjerneld F: Enzyme-catalyzed hydrolysis and recycling in cellulose bioconversion. In Methods in Enzymology. Volume 228. Edited by Walter $\mathrm{H}$, Johansson G. San Diego, CA: Academic Press; 1994:549-558.

37. Girard D, Converse A: Recovery of cellulase from lignaceous hydrolysis residue. Appl Biochem Biotechnol 1993, 39-40:521-533.

38. Waeonukul R, Kosugi A, Prawitwong P, Deng L, Tachaapaikoon C, Pason P, Ratanakhanokchai K, Saito M, Mori Y: Novel cellulase recycling method using a combination of Clostridium thermocellum cellulosomes and Thermoanaerobacter brockii ß-glucosidase. Bioresour Technol 2013, 130:424-430.

39. Liu SY, Wiegel J, Gherardini FC: Purification and cloning of a thermostable xylose (glucose) isomerase with an acidic $\mathrm{pH}$ optimum from Thermoanaerobacterium strain JW/SL-YS 489. J Bacteriol 1996, 178:5938-5945.

40. Middelberg APJ: Process-scale disruption of microorganisms. Biotechnol Adv 1995, 13:491-551.

41. Maki ML, Armstrong L, Leung KT, Qin W: Increased expression of $\beta$-glucosidase a in Clostridium thermocellum 27405 significantly increases cellulase activity. Bioengineered 2013, 4:15-20.

42. Chimtong S, Tachaapaikoon C, Pason P, Kyu KL, Kosugi A, Mori Y, Ratanakhanokchai K: Isolation and characterization of endocellulase-free 
multienzyme complex from newly isolated Thermoanaerobacterium thermosaccharolyticum strain NOI-1.J Microbiol Biotechnol 2011, 21:284-292.

43. Mori Y: Characterization of a symbiotic coculture of Clostridium thermohydrosulfuricum YM3 and Clostridium thermocellum YM4. Appl Environ Microbiol 1990, 56:37-42.

44. Morag E, Bayer EA, Lamed R: Affinity digestion for the near-total recovery of purified cellulosome from Clostridium thermocellum. Enzyme Microb Technol 1992, 14:289-292.

doi:10.1186/1754-6834-6-184

Cite this article as: Prawitwong et al:: Direct glucose production from

lignocellulose using Clostridium thermocellum cultures supplemented with a thermostable $\beta$-glucosidase. Biotechnology for Biofuels 2013 6:184.

\section{Submit your next manuscript to BioMed Central and take full advantage of:}

- Convenient online submission

- Thorough peer review

- No space constraints or color figure charges

- Immediate publication on acceptance

- Inclusion in PubMed, CAS, Scopus and Google Scholar

- Research which is freely available for redistribution 